\title{
Atlas of PET/CT with SPECT/CT
}

\author{
R.L. Wahl and O. Israel \\ Philadelphia, PA: Saunders/Elsevier, 2008, 304 pages, \$207
}

More and more hospitals have expanded imaging services using hybrid PET/CT and SPECT/CT since they are capable of noninvasively demonstrating functional information in an anatomically precise context. This atlas is a multifaceted work that has collected key cases of PET/ $\mathrm{CT}$ and SPECT/CT from 2 busy and experienced clinical services, and it is encyclopedic, comprising a technical introduction, $290 \mathrm{PET} / \mathrm{CT}$ cases with various diseases, and 52 SPECT/CT cases with various radiopharmaceuticals.

The book is organized into 8 sections. Section 1 deals with technical considerations for PET/CT and SPECT/CT. The PET/CT part of this atlas in sections 2 through 7, unlike other similar atlases, is organ site-oriented as opposed to disease type-oriented. This choice was deliberate, since the normal variants and the diseases often occur by region of the body, and the scans are also presented on a regional basis for interpretation. Normal anatomy, variants, artifacts, and typical and uncommon disease patterns from all regions of the body were selected. The SPECT/CT part of the book in section 8, though smaller, is organized according to which radiopharmaceutical was administered, namely ${ }^{111} \mathrm{In}$-pentetreotide, ${ }^{131} \mathrm{I}$-sodium iodide, ${ }^{123} \mathrm{I}$-metaiodobenzylguanidine (MIBG), ${ }^{67} \mathrm{Ga}$-citrate, ${ }^{111} \mathrm{In}$-capromab pendetide, ${ }^{99 \mathrm{~m}} \mathrm{Tc}-$ MIBG, ${ }^{99 \mathrm{~m}}$ Tc-methylene diphosphonate, ${ }^{111}$ In-leukocytes, or ${ }^{99 \mathrm{~m} T c-m e t h o x y i s o b u t y l i s o n i t r i l e . ~ E a c h ~ c a s e ~ c o n s i s t s ~ o f ~}$ a brief history, 1 or 2 panels of registered images, a review of image findings, and a set of salient teaching points as well as a summary. Cases are well illustrated with clear images, although some are relatively small. Combining highresolution CT with PET and SPECT results in precise localization and characterization of tumors based on CT patterns and also in detection of additional small lesions. This book will help bring about more accurate diagnosis and guide effective treatment of tumors and infections.

The electronic cases are a subset of those in the printed atlas, comprising $27 \mathrm{PET} / \mathrm{CT}$ and 6 SPECT/CT cases on DVD with RAPID imaging fusion software provided by Hermes Medical Solutions. The present text with accompanying DVD-ROM, which contains many navigable cases for viewing and analysis, eliminates the potential weakness related to scope and size with this kind of atlas, and it is also useful as teaching material and a source for simulated examinations. There are no references in the text, and the index is conveniently selected.

I highly recommend this atlas to trainees and practitioners in the imaging fields who wish to better interpret $\mathrm{PET} / \mathrm{CT}$ and SPECT/CT.

\author{
E. Edmund Kim \\ M.D. Anderson Cancer Center \\ 1515 Holcombe Blvd., Unit 1264 \\ Houston, TX 77030 \\ E-mail:ekim@di.mdacc.tmc.edu
}

